This is an accepted version of a paper accepted in Journal of Continuing Education in the Health Professions and is not the Version of Record. 


\section{A critical analysis of evidence about the impacts of faculty development in systematic reviews: A Systematic Rapid Evidence Assessment}

Mark Newman ${ }^{1}$, Scott Reeves ${ }^{2}$, Simon Fletcher ${ }^{2}$

1. Social Science Reserch Unit, UCL Institute of Education

2. Centre for Health and Social Care Research, Kingston University and St Georges, University London

Corresponding author:

Mark Newman mark.newman@ucl.ac.uk 


\begin{abstract}
Introduction: Faculty Development (FD) encompasses a range of learning activities undertaken to prepare clinical teachers for their various roles as educators, leaders and scholars. This paper presents the findings of a Systematic Rapid Evidence Assessment (SREA) which aimed to investigate the impact of FD for clinical teachers.
\end{abstract}

Methods: We searched the published and grey literature for systematic reviews of FD to identify evidence to help inform judgements about which kinds of FD activities are effective for which groups of clinical teachers.

Results: After screening the literature we found seven systematic reviews met our inclusion criteria. Following a critical analysis of these reviews we found that they contained a number of limitations in relation to their use of review methods and reporting of results.

Discussion: On the basis of the analysis presented in this SREA we argue that the included reviews do not provide high quality evidence to effectively support decisions about choices of FD activities, even where the review authors made positive claims about impact. We go on to provide suggestions to improve the quality of systematic reviews in this area.

Key words: Faculty Development; healthcare educators; Systematic Rapid Evidence Assessment; critical analysis

\title{
Introduction
}

Different professional groups have different expectations regarding the preparation and accreditation of clinical teachers. ${ }^{1}$ The different kinds of activities undertaken to prepare clinical teachers for their various roles is often referred to collectively as Faculty Development. In this paper, the term Faculty Development (FD) refers to the activities undertaken by teachers of medical and healthcare professionals (from here on referred to as clinical teachers) to improve their knowledge, skills and behaviors as teachers, educators, leaders, managers, researchers and scholars of health professions education. ${ }^{2}$ 
FD activities vary in format, content, duration and setting. As a result, faculty developers have to make important choices when designing and delivering their courses. In these circumstances research evidence about the impacts of FD has a useful role in helping to inform their decisions about which kinds of activities or approaches may be effective for which groups of practitioners in which contexts. ${ }^{3}$ Systematic reviews of research about impacts can provide a comparatively efficient and rigorous source of evidence for this purpose. $^{4}$

This paper presents the findings and discusses the implications for practice and research of our analysis of a number of systematic reviews of FD. These reviews were identified to investigate the following research question: 'which kinds of FD lead to what outcomes for what kinds of clinical teacher?'

\section{Methods}

It is our view that the systematic reviews of FD that we identified and the studies included in them represent a reasonably comprehensive, view of the research literature on the impact of FD within health professions education. It is in this context that we present a summary of the methods we used.

We employed an approach which has been termed a Systematic Rapid Evidence Assessment (SREA). ${ }^{5-6}$ This approach follows the principles of systematic review, however, a number of strategies are used to accelerate a more rapid review process. Specific adaptations employed in this SREA included a selective data extraction process, a limited quality assessment process and a simple synthesis of included materials. In addition, we undertook a 'review of reviews' method, as opposed to reviewing primary research studies in this SREA. This approach has been used by John Hattie and colleagues in the 'Visible Learning Project $^{77}$ and for the Teaching and Learning Toolkit produced by the Education Endowment Foundation. ${ }^{8}$ A SREA approach retains the advantages of transparency and rigor in the review process when compared to non-systematic literature reviews, however, it reduces the time and resources required when undertaking a comprehensive systematic review of primary research. The specific procedures used in this SREA are detailed below. 


\section{Locating systematic reviews}

We searched a range of sources including bibliographic databases (ASSIA, BEI, ERIC, MEDLINE, CINAHL, EMERALD); the Internet (Google Scholar) and systematic review organisations, specifically Cochrane EPOC Group, BEME and the Joanna Briggs Institute. A search string comprising a variety of synonyms for 'Faculty Development' were combined using the Boolean term 'OR' the results of which were then combined with 'AND' systematic review.

\section{Selection criteria}

The following selection criteria were applied to titles and abstracts of provisionally identified materials to identify relevant reviews: (1) reviews investigating the impact of accredited and non-accredited FD for clinical teachers/educators; (2) systematic reviews (i.e. reviews of research with recognized review methods reported); (3) reviews in English since 2000; and (4) reviews containing primary research studies from clinical educational systems which are broadly comparable to the UK in terms of the organization and delivery of health professions education (e.g. mainland Europe, North America, Australasia). A review had to meet all of these criteria to be included. At the second stage of screening (full papers), these selection criteria were re-applied. Figure 1 provides an overview of the searching and screening process.

\section{INSERT FIGURE 1 ABOUT HERE}

\section{Data extraction, analysis and synthesis}

Reviews that met the selection criteria were coded for relevant details about contexts, methods and review results/outcomes using a coding tool developed from previous systematic review work. ${ }^{9}$ A narrative synthesis of included reviews was completed. This narrative involved summarizing and combining the descriptive and contextual and outcome information from the included reviews. The reported outcomes were categorized using a version of Kirkpatrick's outcomes typology adapted by Leslie et al. ${ }^{10}$ (Table 1 ). 
As Table 1 shows, levels 1, 2a, 2b and 3 cover outcomes which measure impact on the clinical teachers who participated a FD intervention; whereas levels $4 a$, 4b and 4c measure impact on organizational practices (e.g. curriculum development), and/or the healthcare students of the participating clinical teachers and/or on the quality of patient care.

\section{Quality assurance processes}

The search strategy and inclusion criteria for this SREA were developed iteratively and piloted. Screening of abstracts was carried out by one of the authors with a random $10 \%$ sample screened by a second author, and any discrepancies discussed and then resolved. Data extraction and coding of key information from the included reviews was undertaken by one of the authors. A second author checked the extracted/coded information from the first two included reviews for consistency. Again, any discrepancies were discussed and then resolved.

\section{Results}

Faculty Development characteristics

Following our literature searches, we initially generated 2480 abstracts (Figure 1). After removing duplicates, the titles and abstracts of 2348 articles were screened using the four selection criteria described above. Seven systematic reviews of FD were included in the analysis. ${ }^{10-16}$ The largest proportion of primary studies in these reviews originated from North America, with a handful of studies from a range of countries, including, Australia, China, Denmark, Germany, Finland, Japan, Israel, Italy, Pakistan, Slovenia, Sweden, and the UK. See Appendix 1 for summaries of the included reviews (Supplementary Digital Content).

\section{Faculty Development content and process}

An overview of FD activities contained in the included reviews is presented in Table 2 . In general, the reviews defined FD as a broad activity encompassing the development of teaching skills/abilities as well as other roles (e.g. administration, scholarship and leadership). However, three of the reviews were more focused: Steinert et al. ${ }^{15}$ on FD activities that promoted leadership; Hill et al. ${ }^{11}$ on FD in the form of 'resident-as-teacher' programmes; and Pearce et al. ${ }^{12}$ in the form of 'train-the-trainer' programmes. 


\section{INSERT TABLE 2 ABOUT HERE}

While all the reviews reported FD activities that involved participants from medicine, three also included study participants from other professional groups, such as dentistry, nursing, occupational therapy, pharmacy, speech therapy, social work. ${ }^{10,12,15}$ However, even in these reviews the majority of included studies were focused on FD for medical practitioners.

According to the included reviews, the majority of the FD activities were undertaken in classrooms or seminar rooms, with very little FD occurring in workplace/based settings. While all the reviews provided an outline description of the different delivery modes (e.g. workshops, retreats, seminars) involved in their included studies, there was a lack of detailed information on specifics of each of these delivery modes. As a result, it was difficult to discern within and across the reviews the exact nature of the FD activities, and the degree of difference or similarity between them. It was not clear whether the lack of detail description reflected a lack of reporting in the individual studies or in the systematic review process, however, a lack of detailed description has been found to be a common feature of intervention research reports. ${ }^{17}$ In contrast, the reviews did provide more information about the duration of the various FD activities included in their respective studies - of which there was quite a lot of heterogeneity across studies, with activities lasting from one hour to three years.

Only one of the reviews ${ }^{13}$ included studies of accredited FD activities which resulted in a certificate of qualification being awarded: eight studies of family medicine fellowships that lead to an advanced degree. The lack of studies of accredited certificated programmes in the reviews is notable given that it has been argued that accreditation is an indicator of the quality of a programme. ${ }^{18}$ Moreover, our personal experience has been that course certification can be a key factor in initial learner engagement. The systematic reviews themselves did not comment on the absence of accreditation in FD programmes. It is not clear whether this absence reflects the relative paucity of accredited FD programmes or rather a lack of impact evaluations of these programmes. 


\section{Reported impact on learning outcomes}

Six of the reviews ${ }^{10-12,14-16}$ provided details of the impact on outcomes categorized as FD activity. One of the reviews however did not offer details of the individual outcomes measured in each study but only aggregated information linking FD to reported outcomes ${ }^{13}$.

We classified the reported outcomes using a modified outcomes typology ${ }^{10}$ (Table 3). The figures in each cell of the table represent the number of outcomes of that type and level reported in the review. The majority of outcomes reported are at level 1 (learner reaction), $2 a$ (changes to learner attitudes/perceptions), 2b (changes to learner knowledge/skills) and 3 (learner behavioral change). Far fewer outcomes are reported for levels $4 a$ (changes to organisations), $4 \mathrm{~b}$ (changes in health care student learning resulting from a FD intervention received by their clinical teacher) or $4 c$ (changes to patient care). Furthermore, most studies in the reviews used self-report data (e.g. surveys, interviews) to measure outcomes from a FD activity (i.e. the outcome measures were based on the learners' own reports about selfperceived change). There appears to be very little outcome data derived from rigorously developed, independent and/or blinded, data sources (e.g. systematic observations of teaching practice).

\section{INSERT TABLE 3 ABOUT HERE}

Across the reviews, FD activities described as 'workshops' and 'longitudinal programs' report the largest amount of outcomes of all types. However, as the reviews did not provide detailed information that described the nature of the included FD activities it is not clear whether (or how) the activities in these categories are similar or different to each other, or to activities in other categories. The review by Steinert et al. ${ }^{16}$ included two outcomes: 'building of a Faculty Development community' and 'building of a community of practice in the workplace' which were not featured in the other reviews. However, unlike the other outcomes reported in in Table 3 (based on results reported in the primary studies), these additional outcomes were based on Steinert and colleagues' own judgements on whether these outcomes had occurred (or not) in the included studies. 


\section{Quality issues in the systematic reviews}

Table 4 summarizes the methods used in the reviews. All seven reviews reported using standard systematic review methods for searching, selecting, abstracting, analysing and report writing. All of the reviews undertook searches that involved the use of several bibliographic databases. All but one ${ }^{13}$ used additional sources to find studies including searches of reference lists of included articles, journal hand searches, expert recommendations. Only one review ${ }^{12}$ appeared to search for studies that were not published in academic journals by searching the Internet.

Given our selection criteria, we anticipated that the identified systematic reviews would have included within them many of the same studies. However, of the 317 references that we identified in the reviews as being an included study (the total number of studies reported in all the reviews themselves was 328), only 38 studies appeared in two of the reviews, and a further two studies appeared in three of the reviews. This seemed unexpectedly low given that all of the reviews were published after 2006 and had search dates that covered roughly similar periods of time. A closer scrutiny of the selection criteria used in each of the reviews suggest in part this was due to the specific way in which individual reviews had focused their respective selection criteria. For example, on a particular group of health professionals, ${ }^{11}$ specific type of FD activity, ${ }^{15}$ or specific study design (only experimental or quasi experimental research designs with control groups ${ }^{12}$ ).

In some cases the authors of a systematic review were clearly aware of at least one of the other systematic reviews included in our SREA, and excluded studies from their own review that had been included elsewhere. For example, Steinert et al. ${ }^{16}$ excluded studies from the Steinert et al. ${ }^{14}$ review. In such cases the justification given was that they wanted to 'develop' or 'build on' the previous review. But this 'development' was not apparent in their review reporting, and indeed it was difficult to see how it could be undertaken in a systematic manner without the inclusion and analysis of the studies in the previous review.

These reviews all reported that a quality assessment of the included studies was completed. The amount of detail about the method of quality assessment reported varied between the reviews. For example, Sorinola \& Thistlethwaite ${ }^{13}$ and Steinert et al. ${ }^{14,16}$ used two 5-point 
scales to assess 'study quality' and 'study findings'. However, both reviews offered little information about how this scoring was operationalized to measure possible threats to validity (bias), or how the scores awarded to the included studies were calculated. In a few of the reviews, the quality scores were simply 'aggregated' across the included studies to provide a mean rating - an approach which does not offer a meaningful insight into the methodological quality of any individual study. By contrast, Pearce et al. ${ }^{12}$ provided a more transparent and systematic approach to quality assessment as they employed a wellestablished 'risk of bias' approach which scored each of the 18 included studies as being at 'high', 'medium' or 'low' risk of bias, using a set of quality criteria based on establishing descriptive causality.

\section{INSERT TABLE 4 ABOUT HERE}

The use of a systematic approach to synthesis is a key element for any systematic review. ${ }^{19}$ In three of the reviews, ${ }^{11,14,16}$ the approach used for synthesizing study results was not reported. In two of the reviews, the synthesis method was described as "narrative"12-13 and in one as "integrated". ${ }^{15}$ Leslie et al. ${ }^{10}$ reported using SPSS to produce a "synthesized descriptive account of the articles". It was not transparent what these methods meant in practice in any of these reviews, other than a descriptive reporting of the results of the individual studies. Furthermore, it was not clear in any of the reviews how study quality assessment ratings were used/incorporated in the process of synthesizing results from individual studies (e.g. through 'weighting' on the basis of study quality), or in the reviewers' interpretation of study findings.

\section{Discussion}

We undertook this SREA in an attempt to generate a comprehensive account of the research evidence about the impacts of FD activities to help inform the decisions about which kinds of activities may be effective for which groups of practitioners in which contexts. We were therefore looking for evidence that facilitated understanding of how much 'benefit' was obtained from a specific outcome, from a specific FD activity for a specific group of clinical teachers. Evidence that facilitated interpretation, comparison of 
different FD approaches and exploration of the various moderators of effect, not simply evidence that 'everything works'.7

With one exception, ${ }^{10}$ the reviews reported that FD activities for clinical teachers resulted in a number of positive impacts. Specifically, they claimed that the use of workshops and longitudinal programs can lead to positive impacts for clinical teachers in relation to their improvement in their reactions, attitudes/perceptions, knowledge/skills and behaviors). A number of these reviews ${ }^{10,13,16}$ also reported that FD activities can generate positive impacts for clinical teaching organisations.

Though the claims made in all seven reviews seemed to be encouraging, there were some common limitations. For example, these reviews contained little information from their included studies about the characteristics of the reported FD activities or any estimate of the amount of benefit obtained from different activities. As a result, one cannot tell, for example, whether a seminar has greater benefit than a workshop or whether the duration of an activity makes any difference to outcomes or whether different FD activities have different outcomes for different clinical teachers.

The majority of studies contained in these reviews measured impact using self-report data, i.e. the learners were asked whether their participation in a FD benefited them in some way. As self-report data rely on an individual's perception, well-known problems with recall and social desirability bias raise questions about the validity of such data as a measure of impact in this context. ${ }^{20-21}$ Consequently, the claims made in the reviews about the impact of FD on learner knowledge, practice and organizational quality is largely based on data with very well-known quality limitations.

Furthermore, the statements about the impacts of FD activity in the reviews imply that outcomes, whatever they may be, are directly attributable to the use of the evaluated FD activity itself. Thus there is a need for these statements to be supported by evidence of descriptive causality ${ }^{22}$. While there is some debate about the relative merits of different research designs for this purpose, the single group post-test only design used to measure 
outcomes in most of the studies in the seven reviews provides a very weak warrant for claims of causality. ${ }^{23}$

It may be argued that the relationship between specific aspects of research design and study outcome is debatable. ${ }^{24}$ It is therefore it is reasonable to include studies using different research designs (notwithstanding the issue of establishing descriptive causality) to investigate the same research question within in a systematic review. However, where this is the case we would expect that the effects of heterogeneity of study design would be one of the factors explored as part of the analysis within a systematic review. Unfortunately, there was a limited quality assessment of the included studies in most reviews and no assessment of heterogeneity. Furthermore with one exception, ${ }^{12}$ the individual study quality assessment methods used in reviews, did not appear to be linked to establishing a warrant for a causal claim i.e. it is not clear what the quality assessment judgement for any study means, e.g. 'good' but for what?

\section{Implications}

We undertook the SREA to identify evidence to help inform the decisions about which kinds of FD activities may be effective for which groups of clinical teachers in which contexts. Due to the accelerated nature of the SREA approach we may have missed other evidence and/or details about the quality of evidence that was reviewed. ${ }^{5-6}$ However, our analysis of these reviews identified numerous limitations in reporting and methods. These limitations mean that individually and collectively these reviews do not provide practitioners with detailed, transparent and rigorous evidence that can inform choices in practice in the way that we hoped they would, even where the review authors claim they do.

In terms of developing the evidence base for FD in future, one step to consider is whether the evidence could be improved by more detailed systematic review of individual studies of the impact of FD contained within these reviews. It does appear that in some of these reviews there were studies which investigated the impact of FD activities using research designs that are explicitly concerned with establishing a warrant for descriptive causality, for example, the studies in the Pearce et al. review. ${ }^{12}$ It may be useful to identify these studies as the basis for a new systematic review of the evidence. 
However, even if a new review was carried out using these studies it would appear that it would only cover a limited range of FD types (e.g. 'Train the Trainer' model ${ }^{12}$ ), be limited to self-reported learning outcomes, and only include medical teachers. Therefore, while such a review may give us more confidence about the quality of the evidence, it would be focused on a limited range of FD activities in a limited range of contexts. There may be other relevant studies that were not included in these reviews. However, based on our knowledge of research in this field we suspect that this will add to the quantity of the evidence base, but without necessarily strengthening the warrant for claims about for impact. Given these limitations, it would seem imperative that commissioners and providers of FD activities work together with researchers to improve the quality of the evidence in this area. This work could focus on improving the systematic descriptive reporting of FD activities using something similar to the TIDieR Checklist, ${ }^{25}$ and also considering the requirements for demonstrating descriptive causality when designing evaluations of FD activities.

The findings of our analysis also provide some food for thought for the community about the scope and methods of systematic reviews in this field. Our initial excitement at identifying seven systematic reviews of the impact of FD of recent provenance and apparently broad scope did not yield the results we anticipated. Two particular issues stand out here. Although the systematic reviews appeared to follow the methods of systematic review in their early stages, i.e. searching, selection, use of quality assurance processes, they did not use systematic transparent synthesis methods that incorporated assessment of individual study quality. Without this it is not possible to make judgements about the warrant for any claim about the impact of, for example, different types of FD activities, or to assess any potential causes of heterogeneity of outcome such as study design. Labelling whatever process of synthesis which was undertaken as 'narrative' or 'integrated' does not substitute for detailed systematic synthesis reporting. The omission of this key stage in the systematic review process undermines the potential value of such reviews considerably.

A second issue is the way in which reviews are focused. The systematic reviews included in this SREA were focused either on a particular type of FD, a particular health profession 
and/or a desire to expand on other reviews. While this may seem like a reasonable approach for an individual review it does not appear to be leading toward a coherent comprehensive account of the field as a whole. We are not clear how this can be addressed given the prevailing disciplinary/professional boundaries, academic incentives and limited funding. Nevertheless, there may be a role for collaborations such as BEME, The Cochrane Collaboration, The Campbell Collaboration or the Joanna Briggs Institute in seeking to manage curation of relevant studies and coordinate reviews. At the very least it would seem appropriate for reviews seeking to 'build on' or 'develop' from other systematic reviews to do so in a systematic transparent fashion. For example, a review that is intended to update or expand upon an existing review should include the studies from the original review in a revised synthesis. Given the limitations we identified in the seven included FD reviews, this is likely to mean re-analyzing the studies from the first review with any newly identified studies in a completely new systematic review.

\section{References}

1. Austerberry A \& Newman M. Review of qualifications and training for clinical educators in the healthcare professions. London. London Deanery; 2013. Available at: http://www.faculty.londondeanery.ac.uk/other-resources/review-of-qualifications-andtraining-for-clinical-teachers-in-the-healthcare-professions-4

2. Steinert Y. Faculty Development: Future Directions. In: Steinert Y. (eds) Faculty Development in the Health Professions. Innovation and Change in Professional Education, vol 11. Springer, Dordrecht; 2014

3. Stritter F. Faculty evaluation and development. In: C McGuire, R Foley, A Gorr, RRichards (eds). Handbook of Health Professions Education. San Francisco, Calif: Jossey Bass; (p294-318); 1983.

4. Davies, P. What is evidence-based education? British Journal of Educational Studies, 1999; 47(2) $108-121$

5. Thomas J, Newman M, Oliver S. Rapid evidence assessments of research to inform social policy: taking stock and moving forward. Evidence and Policy, 2013; 9: 5-27.

6. Ganann R, Ciliska D, Thomas H. Expediting systematic reviews: methods and implications of rapid reviews. Implementation Science, 2010; 5:56. DOI: https://doi.org/10.1186/1748-5908-5-56

7. Hattie J. Visible learning: A synthesis of over 800 meta-analyses relating to achievement. London Routledge; 2009 
8. Higgins, S. Meta-synthesis and comparative meta-analysis of education research findings: some risks and benefits, Review of Education, 2016; 4.1: 31-53. DOI: http://dx.doi.org/10.1002/rev3.3067

9. Reeves S, Fletcher S, Barr H, Birch I, Boet S, Davies N, McFadyen A, Rivera J, Kitto S. A BEME systematic review of the effects of interprofessional education: BEME Guide No. 39. Medical Teacher, 2016; 38(7):656-68

10. Leslie, K, Baker, L, Egan-Lee, E, Esdaile, M, Reeves, S. Advancing Faculty Development in medical education: A systematic review, Academic Medicine, 2013; 88: 1038-1045

11. Hill, A. G, Tzu-Chieh, Y, Barrow, M, Hattie, J. A systematic review of resident-as-teacher programmes, Medical Education, 2009; 43: 1129-1140

12. Pearce, J, Mann, M. K, Jones, C, Buschbach, S, Olff, M, Bisson, J. The most effective way of delivering a Train-the-Trainers program: A systematic review, Journal of Continuing Education in the Health Professions, 2012; 32: 215-226

13. Sorinola, $\mathrm{O}$, Thistlethwaite, J. A systematic review of Faculty Development activities in family medicine, Medical Teacher, 2013; 35: 1309-1318

14. Steinert, Y, Mann, K, Centeno, A, Dolmans, D, Spencer, J, Gelula, M, Prideaux, D. A systematic review of Faculty Development initiatives designed to improve teaching effectiveness in medical education: BEME Guide No. 8, Medical Teacher, 2006; 28: 497526

15. Steinert, Y, Naismith, L, Mann, K. Faculty Development initiatives designed to promote leadership in medical education. A BEME systematic review: BEME Guide No. 19, Medical Teacher, 2012; 34: 483-503

16. Steinert, Y, Mann, K, Anderson, B, Barnett, B, Centeno, A, Naismith, L, Prideaux, D, Spencer, J, Tullo, E, Viggiano, T, Ward, H, Dolmans, D. A systematic review of Faculty Development initiatives designed to enhance teaching effectiveness: A 10-year update: BEME Guide No. 40, Medical Teacher, 2016; 38: 769-786

17. Hoffmann TC, Oxman AD, loannidis JPA, Moher D, Lasserson TJ, Tovey DI, Stein K, Sutcliffe K, Ravaud P, Altman DG, Perera R. Enhancing the usability of systematic reviews by improving the consideration and description of interventions. BMJ, 2017;357:j2998

18. Harvey L. A history and critique of quality evaluation in the UK. Quality Assurance in Education, 2005; Vol. 13 (4) pp.263-276

19. Gough D \& Thomas J.Commonality and diversity in reviews in In Gough D, Oliver S, Thomas J (Eds) An Introduction to Systematic Reviews (2nd Edition), London: Sage, 4370; 2017 
20. Bowman NA \& Hill PL. Measuring how college affects students: Social desirability and other potential biases in college student self-reported gains. New Directions for Institutional Research, 2011; 150, 73-85

21. Pike GR. Using college students' self-reported learning outcomes in scholarly research, New Directions for Institutional Research, 2011; 150, 41-48

22. Newman M. Fitness for purpose evaluation in Problem Based Learning should consider the requirements for establishing descriptive causation. Advances in Health Sciences Education, 2006; 11, 391-402

23. Torgerson, C. \& Torgerson, D. The need for randomised controlled trials in educational research. British Journal of Educational Studies, 2001; 49, 316-318.

24. Wells, K \& Littell JH. Study quality assessment in systematic reviews of research on intervention effects. Research on Social Work Practice, 2009; 19(1), 52-62

25. Hoffmann TC, Glasziou PP, Boutron IP, Milne R, Perera R, Moher D, Altman DG, Barbour V, Macdonald $H$, Johnston M, Lamb SE, Dixon-Woods M, McCulloch P, Wyatt JC, Chan AC, Michie S, Better reporting of interventions: template for intervention description and replication (TIDieR) checklist and guide. BMJ, 2014; 348:g1687

\section{Implications for practice}

- Faculty Development (FD) is a key activity to support the professional growth (knowledge, skills and abilities) of clinical teachers.

- While research about the impact of FD is growing, this Systematic Rapid Evidence Assessment (SREA) found that the positive claims made about the impact of FD in seven systematic reviews contained number of key limitations which generated uncertainty about their reported outcomes.

- To improve the quality of future systematic reviews of FD, reviewers need to address the methodological shortfalls identified in this SREA, paying particular attention to providing more transparency in their work. 
Figure 1: Searching and screening results

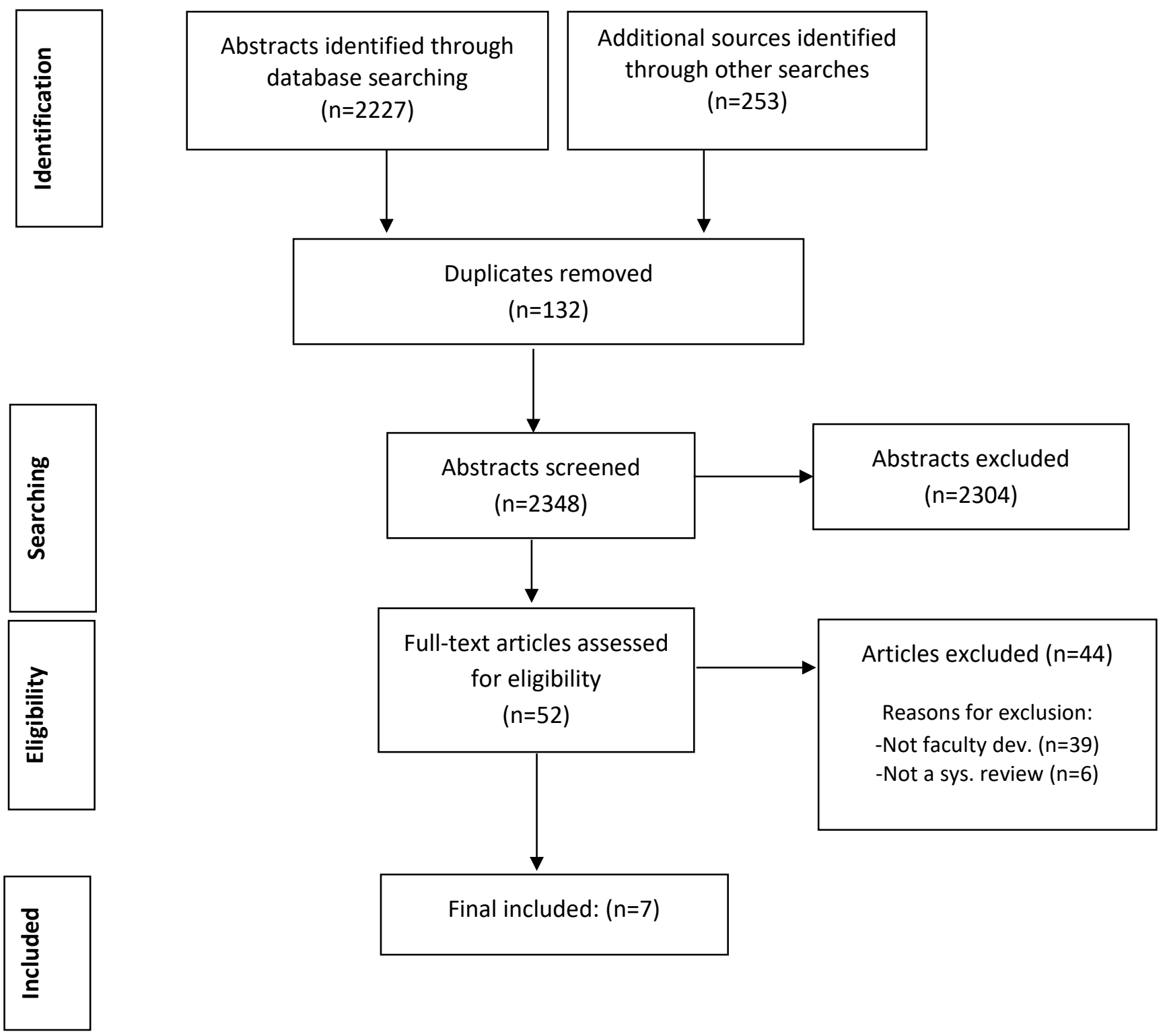


Table 1: Key Outcomes

\begin{tabular}{|l|l|}
\hline Outcome & Description \\
\hline 1. Reaction & $\begin{array}{l}\text { Participants' views on the learning experience, its organisation, } \\
\text { presentation, content, teaching methods, and quality of } \\
\text { instruction }\end{array}$ \\
\hline $\begin{array}{l}\text { 2a. Learning/change in } \\
\text { attitudes }\end{array}$ & $\begin{array}{l}\text { Changes in the attitudes or perceptions among participant } \\
\text { groups towards teaching and learning }\end{array}$ \\
\hline $\begin{array}{l}\text { 2b. Learning/modification of } \\
\text { knowledge or skills }\end{array}$ & $\begin{array}{l}\text { For knowledge, this relates to the acquisition of concepts, } \\
\text { procedures and principles; for skills, this relates to the } \\
\text { acquisition of thinking/problem-solving, psychomotor and social } \\
\text { skills }\end{array}$ \\
\hline $\begin{array}{l}\text { 3. Learning/ Behavioural } \\
\text { change }\end{array}$ & $\begin{array}{l}\text { The transfer of learning to the workplace (i.e in teaching) or } \\
\text { willingness of learners to apply new knowledge and skills }\end{array}$ \\
\hline $\begin{array}{l}\text { 4a. Change in the } \\
\text { system/organisational } \\
\text { practice }\end{array}$ & $\begin{array}{l}\text { Wider changes in the organisation, attributable to the clinical } \\
\text { teacher Faculty Development activity (e.g. curricula changes) }\end{array}$ \\
\hline $\begin{array}{l}\text { 4b. Change among learners } \\
\text { of the clinical teachers }\end{array}$ & $\begin{array}{l}\text { Changes to healthcare student learning/performance as a result } \\
\text { of the Faculty Development activities }\end{array}$ \\
\hline $\begin{array}{l}\text { 4c. benefits to patients/ } \\
\text { Communities }\end{array}$ & $\begin{array}{l}\text { Benefits to patients/wider public/communities as a result of the } \\
\text { Faculty Development }\end{array}$ \\
\hline
\end{tabular}


Table 2: Information on Faculty Development activities

\begin{tabular}{|c|c|c|c|}
\hline $\begin{array}{l}\text { Review } \\
\text { citation }\end{array}$ & $\begin{array}{l}\text { Faculty Development } \\
\text { focus }\end{array}$ & Learning activities & Duration (range) \\
\hline Hill et al. 2009 & $\begin{array}{l}\text { Resident-as-teacher } \\
\text { (medicine) }\end{array}$ & $\begin{array}{l}\text { Workshops, retreats, } \\
\text { seminars, lectures, } \\
\text { residential courses }\end{array}$ & $\begin{array}{l}\text { From one hour to } \\
\text { three days }\end{array}$ \\
\hline $\begin{array}{l}\text { Leslie et al., } \\
2013\end{array}$ & $\begin{array}{l}\text { Faculty Development } \\
\text { (medicine \& } \\
\text { interprofessional, e.g. } \\
\text { nursing, pharmacy, } \\
\text { public health, dentistry) }\end{array}$ & $\begin{array}{l}\text { Longitudinal courses, } \\
\text { workshops, short } \\
\text { courses, fellowships }\end{array}$ & $\begin{array}{l}\text { From a few hours } \\
\text { to two years }\end{array}$ \\
\hline $\begin{array}{l}\text { Pearce et al. } \\
2012\end{array}$ & $\begin{array}{l}\text { Train-the-trainer } \\
\text { (all professions, e.g. } \\
\text { medicine, nursing, } \\
\text { psychology, social work)) }\end{array}$ & $\begin{array}{l}\text { Lectures, interactive } \\
\text { exercises, case studies, } \\
\text { role-plays }\end{array}$ & Around three days \\
\hline $\begin{array}{l}\text { Sorinola \& } \\
\text { Thistlethwaite, } \\
2013\end{array}$ & $\begin{array}{l}\text { Faculty Development } \\
\text { (medicine) }\end{array}$ & $\begin{array}{l}\text { Seminar, workshops, } \\
\text { short courses, } \\
\text { longitudinal courses, } \\
\text { fellowships }\end{array}$ & $\begin{array}{l}\text { From a few hours } \\
\text { to two years }\end{array}$ \\
\hline $\begin{array}{l}\text { Steinert et al. } \\
2006\end{array}$ & $\begin{array}{l}\text { Faculty Development } \\
\text { (medicine) }\end{array}$ & $\begin{array}{l}\text { Workshops, seminar } \\
\text { series, short courses, } \\
\text { fellowships, longitudinal } \\
\text { programs, other FD } \\
\text { activities (e.g. feedback } \\
\text { sessions, coaching, site } \\
\text { visits) }\end{array}$ & $\begin{array}{l}\text { From one hour to } \\
18 \text { months }\end{array}$ \\
\hline $\begin{array}{l}\text { Steinert et al. } \\
2012\end{array}$ & $\begin{array}{l}\text { Faculty Development } \\
\text { (leadership, medicine \& } \\
\text { interprofessional, e.g. } \\
\text { dentists, nurses, } \\
\text { pharmacists, public } \\
\text { health) }\end{array}$ & $\begin{array}{l}\text { Workshops, short } \\
\text { courses, longitudinal } \\
\text { programs, seminar } \\
\text { series, fellowships, other } \\
\text { FD activities (e.g. } \\
\text { feedback sessions, } \\
\text { coaching, site visits) }\end{array}$ & $\begin{array}{l}\text { From two hours to } \\
\text { three years }\end{array}$ \\
\hline $\begin{array}{l}\text { Steinert et al. } \\
2016\end{array}$ & $\begin{array}{l}\text { Faculty Development } \\
\text { (medicine) }\end{array}$ & $\begin{array}{l}\text { Workshops, Longitudinal } \\
\text { programs } \\
\text { Fellowships, short } \\
\text { courses, seminar series }\end{array}$ & $\begin{array}{l}\text { From } 30 \text { minutes } \\
\text { to four years }\end{array}$ \\
\hline
\end{tabular}


Table 3: Activities \& Reported Outcomes

\begin{tabular}{|c|c|c|c|c|c|c|c|c|}
\hline \multirow[b]{2}{*}{ Review } & \multirow[b]{2}{*}{ Activities } & \multicolumn{7}{|c|}{ Reported outcomes (per study) } \\
\hline & & Level 1 & $\begin{array}{l}\text { Level } \\
2 a\end{array}$ & $\begin{array}{l}\text { Level } \\
2 b\end{array}$ & Level 3 & Level 4a & $\begin{array}{c}\text { Level } \\
4 b\end{array}$ & Level 4c \\
\hline \multirow[t]{6}{*}{ Hill et al. 2009} & Seminars/tutorials & 2 & 3 & 1 & 1 & - & - & 1 \\
\hline & Workshops/follow-up & - & 1 & 1 & 2 & - & - & - \\
\hline & Teaching sessions & 4 & 3 & 3 & 5 & - & - & - \\
\hline & Workshops & 8 & 6 & 6 & 8 & - & - & - \\
\hline & Retreats & - & - & 1 & 2 & 1 & - & - \\
\hline & Retreats/follow-up & - & 2 & 1 & 1 & 1 & - & - \\
\hline \multirow{5}{*}{$\begin{array}{l}\text { Leslie et al. } \\
2013\end{array}$} & Longitudinal courses & 6 & 9 & 11 & 12 & 6 & 2 & 2 \\
\hline & Workshops & 1 & 2 & 3 & 4 & 2 & 2 & - \\
\hline & Short courses & 1 & - & 1 & 2 & 1 & - & - \\
\hline & Other courses & 1 & 1 & 1 & 1 & 1 & - & - \\
\hline & Fellowship & - & 1 & - & 1 & - & - & - \\
\hline \multirow{4}{*}{$\begin{array}{c}\text { Pearce et al. } \\
2012\end{array}$} & Didactic & - & - & 1 & 1 & - & - & 1 \\
\hline & Didactic/interactive & - & 1 & 3 & 4 & - & - & 3 \\
\hline & Interactive & - & - & 1 & 2 & - & - & - \\
\hline & Not stated & - & - & 1 & 1 & - & - & - \\
\hline $\begin{array}{c}\text { Sorinola \& } \\
\text { Thistlethwaite, } \\
2013\end{array}$ & 'Faculty Development' ${ }^{\prime}$ & 28 & 10 & 20 & 23 & 10 & - & - \\
\hline \multirow{6}{*}{$\begin{array}{l}\text { Steinert et al. } \\
2006\end{array}$} & Workshops & 16 & 7 & 15 & 17 & 2 & 2 & \\
\hline & Seminar series & 7 & 4 & 7 & 7 & 3 & - & \\
\hline & Short courses & 6 & 2 & 2 & 4 & 1 & - & \\
\hline & Longitudinal programs & 1 & 1 & 1 & 1 & - & - & \\
\hline & Fellowships & 2 & 2 & 3 & 2 & 1 & - & \\
\hline & Other FD activities ${ }^{2}$ & 8 & 4 & 2 & 8 & - & 2 & \\
\hline
\end{tabular}




\begin{tabular}{|c|c|c|c|c|c|c|c|}
\hline \multirow{5}{*}{$\begin{array}{c}\text { Steinert et al. } \\
2012^{3}\end{array}$} & Workshops & 3 & 2 & 1 & 3 & - & \\
\hline & Longitudinal programs & 11 & 8 & 12 & 18 & 6 & \\
\hline & Fellowships & 6 & 7 & 9 & 12 & 2 & \\
\hline & Short courses & 2 & 1 & 1 & 2 & - & \\
\hline & Seminar series & - & - & 1 & 1 & - & \\
\hline \multirow{5}{*}{$\begin{array}{c}\text { Steinert et al. } \\
2016^{3,4}\end{array}$} & Workshops & 17 & 15 & 15 & 24 & 6 & 1 \\
\hline & Short courses & 7 & 8 & 9 & 13 & 3 & 1 \\
\hline & Seminar series & 6 & 6 & 7 & 8 & 2 & 2 \\
\hline & Longitudinal programs & 20 & 19 & 27 & 36 & 16 & - \\
\hline & Other FD activities ${ }^{5}$ & 7 & 4 & 4 & 12 & - & 2 \\
\hline
\end{tabular}

\section{Notes}

${ }^{1}$ Specific activities not identified

${ }^{2}$ Covers a range of one-off Faculty Development activities such as, feedback sessions, single seminars; one-to-one coaching, site visit, one-hour conference

${ }^{3}$ Divided behaviour outcomes (level 3) into two separate categories: self-reported changes and observed changes

${ }^{4}$ Included 2 new outcomes (a) intervention led to building of Faculty Development community, (b) intervention led to building a community of practice

${ }^{5}$ Specific activities not identified

(The shaded area indicates that a review did not include this level of outcome) 
Table 4: Review methods

\begin{tabular}{|c|c|c|c|}
\hline & $\begin{array}{l}\text { Study selection } \\
\text { criteria* }\end{array}$ & Searches and results & $\begin{array}{l}\text { Synthesis } \\
\text { method }\end{array}$ \\
\hline Hill et al. 2009 & $\begin{array}{l}\text { Medical } \\
\text { Residents/ } \\
\text { registrars only }\end{array}$ & $\begin{array}{l}\text { Search Dates } 1971-2008 \\
8 \text { databases \& reference lists of } \\
\text { included studies } \\
10865 \text { abstracts \& } 288 \text { articles } \\
\text { screened } \\
29 \text { included studies }\end{array}$ & Not reported \\
\hline $\begin{array}{l}\text { Leslie et al. } \\
2013\end{array}$ & $\begin{array}{l}\text { Excluded } \\
\text { articles } \\
\text { included in } \\
\text { 'other Faculty } \\
\text { Development } \\
\text { systematic } \\
\text { reviews. } \\
\text { Only papers in } \\
\text { peer reviewed } \\
\text { journals. }\end{array}$ & $\begin{array}{l}\text { Search dates: } 1989-2010 \\
-3 \text { databases; journal hand searches } \\
-18181 \text { abstracts } \& 271 \text { articles } \\
\text { screened } \\
-22 \text { included studies }\end{array}$ & Not reported \\
\hline $\begin{array}{l}\text { Pearce et al. } \\
2012\end{array}$ & $\begin{array}{l}\text { Only 'Training } \\
\text { The Trainers' } \\
\text { activities Only } \\
\text { Experimental } \\
\text { and quasi } \\
\text { experimental } \\
\text { design }\end{array}$ & $\begin{array}{l}\text { Search dates: Not reported } \\
\text {-15 databases; } \\
\text { reference lists; web resources } \\
\text {-22858 abstracts \& } 228 \text { articles } \\
\text { screened } \\
19 \text { included studies }\end{array}$ & $\begin{array}{l}\text { Meta-analysis } \\
\text { not possible so } \\
\text { narrative } \\
\text { synthesis }\end{array}$ \\
\hline $\begin{array}{l}\text { Sorinola \& } \\
\text { Thistlethwaite, } \\
2013\end{array}$ & $\begin{array}{l}\text { Family } \\
\text { Medicine } \\
\text { (medical) only }\end{array}$ & $\begin{array}{l}\text { Search Dates }-1980-2010 \\
-4520 \text { abstracts \& } 66 \text { articles } \\
\text { screened } \\
-46 \text { included studies }\end{array}$ & Narrative \\
\hline $\begin{array}{l}\text { Steinert et al. } \\
2006\end{array}$ & $\begin{array}{l}\text { Only Medical, } \\
\text { not } \\
\text { Residents/regist } \\
\text { rars as teachers }\end{array}$ & $\begin{array}{l}\text { Search Dates: 1980-2002 } \\
-3 \text { databases, journal hand searches } \\
-2777 \text { abstracts \& } 303 \text { articles } \\
\text { screened } \\
-53 \text { included studies }\end{array}$ & Not reported \\
\hline $\begin{array}{l}\text { Steinert et al. } \\
2012\end{array}$ & $\begin{array}{l}\text { Leadership } \\
\text { focus, } \\
\text { outcome data } \\
\text { beyond } \\
\text { participant } \\
\text { satisfaction }\end{array}$ & $\begin{array}{l}\text { Search dates: } 1980-2009 \\
-6 \text { databases, journal hand searches, } \\
\text { expert recommendations } \\
-530 \text { abstracts \& } 75 \text { articles screened } \\
-48 \text { included studies }\end{array}$ & $\begin{array}{l}\text { An integrated } \\
\text { design. }\end{array}$ \\
\hline
\end{tabular}




\begin{tabular}{|l|l|l|l|}
\hline Steinert et al. & Only Medical, & Search Dates: 2002-2012 & Not reported \\
& not & -4 databases, journal hand searches, & \\
& Residents/regist & conferences, expert & \\
& rars as teachers & recommendations & \\
& Not included in & -871 abstracts \& 215 articles & \\
& Steinert 2006 & screened & \\
& review & -111 included studies & \\
\hline
\end{tabular}

*Only refers to selection criteria specific to the review 


\section{Appendix 1: Summaries of the included Faculty Development reviews}

Hill et al. (2009)

These authors report on a review which aimed to investigate the effectiveness of medical resident-as-teacher (RaT) programmes on teaching abilities. The authors provide a broad definition of a RaT activity, as any programme/intervention whose main purpose is to improve resident teaching abilities. The authors searched a range of sources including PubMed, EMBASE, ERIC and CINAHL from 1971 to 2008. Following the screening of abstracts and full articles, 29 studies were located from the following countries: USA; Canada; Denmark; The Netherlands; Pakistan and Australia. Training activities ranged from one-hour teaching sessions to three-day training-courses involving workshops, seminars, lectures, retreats and residential courses. The RaT training programmes focused on residents in internal medicine, family medicine, paediatrics, obstetrics and gynaecology. None of the included studies reported providing any form of certification. Of the 29 studies included, seven used a randomised control design, while 10 used non-randomised study designs. Ten studies used a single-group study design (eight of which employed pre/post-intervention approaches and two used a post-intervention only approach). The remaining two studies were descriptive case studies. In regards to the outcomes, Hill et al (2009) report that overall satisfaction with the RaT programmes was reported as high (14 studies). It was also reported that participants reported positive changes in attitudes towards teaching ( 21 studies) and improvements in knowledge of educational principles and teaching ability improved (18 studies). In addition, a very small number of studies reported changes to organisational practice (three studies), benefits to learners of the teachers/faculty developers (one study). The vast majority of these outcomes were based on self-reported data (surveys, interviews). However, eight studies did include direct observation of teaching performance. Based on their findings, the authors offer the following four conclusions: "firstly, although the RaT programmes were all designed to improve the effectiveness of resident clinical teaching skills, this is a group of heterogeneous interventions. The programmes vary significantly in terms of content, delivery and duration. Secondly, there is currently little to suggest significant international experience because the majority of literature originates from North America. Thirdly, overall results from this review indicate that RaT programmes receive positive responses from participating residents and that they lead to changes in attitudes and perceptions about teaching. Lastly, the effectiveness of RaT programmes for improving resident teaching skills and the learning experience of medical students remains unclear, largely because the studies reviewed did not examine these outcomes in a systematic and objective manner." (p1137).

Leslie et al. (2013)

These authors completed a review which aimed to describe the range of Faculty Development activities that have been implemented and evaluated in medical education. However, interprofessional activities were included if they involved participants from medicine. Faculty Development was defined as strategies to improve faculty members' teaching performance, as well as other faculty roles, including administration, scholarship and leadership. The authors searched three databases (MEDLINE, CINAHL and ERIC) as well as journal hand searches from 1989 to 2010 and after screening potential materials, located 21 studies from USA, Canada, Israel, Sweden and Germany. While 15 studies involved physicians only, six included a mix of health professionals (nursing, pharmacy, public health, 
dentistry, basic science, and rehabilitation science). Thirteen studies were 'longitudinal' (a series of activities delivered over a number of days, weeks or months) with the remainder being single workshops or short courses. In relation to methodological issues, of the included studies, 12 studies used quantitative study designs (usually employing a pre/postintervention design), eight used mixed methods and two studies employed a qualitative approach. Fifteen of the included studies contained some form of longitudinal element, collecting follow-up data from two months to 13 years post intervention. In addition, nine studies included a control or comparison group in their design. None of the included studies reported providing any form of certification. Leslie et al (2013) reported that most included studies reported gains to participants' satisfaction (nine studies), improved motivation, selfconfidence (14 studies) as well as increases in teaching knowledge/skills (16 studies) and individual teaching ability ( 21 studies). A few studies also reported changes to organisational practice (nine studies), benefits to learners of the teachers/faculty developers (three studies) or patients (two studies). All outcomes were based on self-reported data. In conclusion, the review authors state "our findings demonstrate a continued expansion in the scope of the Faculty Development literature. Although our review identified a number of improvements in the design, delivery, and evaluation of Faculty Development activities, it also highlighted areas that require further development. Future Faculty Development work should focus on the use of interprofessional education, the efficacy of work-based Faculty Development activities, and the effects of different organizational and contextual factors. Future research also should employ more rigorous evaluation methods to measure the impact of Faculty Development programs." (p1043).

\section{Pearce et al. (2012)}

These authors undertook a review that aimed to examine the effectiveness of train-thetrainer (TTT) for training health and social care professionals. A TTT activity was defined as one where participants were being trained in a topic (e.g. mental health, counselling) who then go on to train others in this topic following their training. A wide range of databases were searched from their date of inception to 2011 which resulted, after screening processes, in the identification of 18 studies including a number of professional groups (e.g. physicians, nurses, psychologists, social workers) from ten countries including USA, Italy, Canada, Sweden, Finland and China. It was found that TTT activities were delivered using a range of learning methods: lecture, interactive exercises, case studies and role-plays usually over three days. None of the included studies reported providing any form of certification. Due to a restrictive methodological inclusion criteria, only including experimental study designs (where there was a control group and follow-up outcomes were measured more than one week after the intervention was delivered), the authors reported that three types of quantitative study design were employed in the included studies: randomized controlled trial design (eight studies), controlled before-and after design (six studies) and a controlled clinical trial design (four studies). The authors found that while most of the TTT programs in 13 studies supported increases to knowledge, improvements to individual teaching behaviour, or helped produce better patient outcomes, one study showed no effect. In addition, it was found that three studies showed possible effect and one study showed that the use of self-directed electronic method was more effective than a traditional face-to-face TTT training method in improving participants' knowledge. Outcomes reported in this review were based on a range of different measures, including, knowledge tests, self-report and clinical outcomes data. The authors conclude that, "this review has shown that TTT 
programs have the potential to effectively disseminate information to health and social care professionals. It appears that using a blended learning approach, combining different techniques and materials, is likely to achieve the best results. Further research is needed to determine the best "blend" of techniques and how they impact on participant and patient/client facing outcome measures." (p224).

\section{Sorinola \& Thistlethwaite (2013)}

These authors undertook a review to assess the evidence for the effectiveness of family medicine Faculty Development activities. These authors define Faculty Development as a planned programme to prepare faculty members for their teaching, research, administration roles, help manage their careers as well as prepare them to meet the goals, vision and mission of the institution (e.g. organisational and leadership development). Databases were searched from 1980 to 2010. Journal hand searches and experts' recommendations of possible review articles were also used to locate possible studies. After screening potential abstracts and papers, 46 studies were identified from six countries (USA, Canada, Slovenia, Germany, United Kingdom and Japan). Of the included studies, 17 used a pre-test/post-test design while 14 used post-test only - none of these studies were randomised and only two studies used a comparison group). In addition, 13 studies employed a mixed methods design and five studies used qualitative designs. It was found that although the content and methods of these included activities varied, programmes shared common goals such as increasing participants' knowledge and teaching skills. It was also found that Faculty Development in family medicine tended to be delivered as short courses or workshops. However, 14 were described as 'longitudinal', a small number of which were fellowships that led to advanced degrees or accredited university awards. Positive outcomes were reported in the included studies at a number of levels, specifically, reactions (23 studies), attitudes/perceptions (10 studies), skills/knowledge (23 studies), individual behaviour (23 studies) and organisational practice (10 studies). However, these outcomes were all measured by self-reported data. Based on their results, the authors conclude that, "Faculty Development activities appear highly valued by the participants, leading to changes in learning and behaviour. Changes in organisational practice and student learning were not frequently reported. while no conclusions can be made as to the most effective Faculty Development activity or the optimal time for reinforcement, it is probably the experience of Faculty Development rather than the particulars of length, content or delivery that have lasting importance." (p1316).

\section{Steinert et al. (2006)}

These authors completed a review to understand the effects of Faculty Development interventions on the knowledge, attitudes and skills of teachers in medical education. In this review, Faculty Development was defined as interventions designed to improve teaching effectiveness, all types of activities, of whatever duration, were included. Three databases and five journals were searched from 1980 to 2002. In addition, conference proceedings, reference lists of review articles and experts' recommendations were included in the search. After screening processes were employed, 53 studies were located from eight countries including: USA; UK; Canada and Switzerland. The Faculty Development activities included in these studies were mostly aimed at improving clinical teaching with a secondary emphasis on feedback/evaluation, small group teaching or lecturing skills. These activities were delivered over a wide range of durations, from one hour to 18 months year in either 
workshops seminars, short courses or fellowships for participants from mostly family medicine and internal medicine backgrounds. None of the included studies reported providing any form of certification. The majority of included studies $(n=47)$ used quasiexperimental designs (with two including comparison groups). Of the 45 single-group designs, 31 employed a pre/post-test designs, 14 studies used a post-test design only. Six used randomized controlled trial designs. None of the studies used a qualitative approach alone, though 11 incorporated qualitative data collection/analysis as part of their study. Positive outcomes were reported in the included studies at a number of levels, specifically, reactions (39 studies), attitudes (19 studies), skills/knowledge (31 studies), individual behaviour (12 studies), organisational practice (seven studies) and among learners of the teachers/faculty developers (three studies). Again, these outcomes were all measured by self-reported data. In conclusion, the authors state that "although many of the studies employed weak designs, making definitive statements about outcome difficult, the literature suggests positive changes in teachers' knowledge, attitudes and skills following participation in a Faculty Development activity. The impact on the organization (i.e. the learners and the systems in which our teachers work) is yet to be fully determined. Moreover, although many of the reported interventions were complex in nature (i.e. comprising different educational strategies and methods), few studies focused on teasing apart 'key features' of effective programs" (p518).

\section{Steinert et al. (2012)}

These authors undertook a review to synthesise evidence related to the effects of Faculty Development interventions designed to improve leadership abilities. Specifically, the review aimed to examine the literature on Faculty Development programs that target leadership capabilities among faculty members and try to assess which programs were most effective. Interventions of interest for this review include all activities focused on the development of leadership abilities (knowledge, skills, and/or attitudes) with leadership being broadly envisioned to include all aspects of management and administration. Five databases were searched from 1980-2009. Hand searches of personal files and reference sections of all retrieved articles were searched and expert recommendations and authors of previously identified articles were also included. Following screening of possible abstracts and articles, 41 studies were located from USA, Canada and UK. The included studies incorporated a wide variety of aims, including enhancing faculty leadership skills, using organizational development principles to enhance leadership and developing a cadre of leaders in various academic disciplines and professions. These Faculty Development activities were offered in a range of formats (workshops, courses, seminars, fellowships) and delivered in differing durations, from a few hours, to one day, to six months and two years to participants from medicine, or to interprofessional groups including dentists, nurses, pharmacists, public health professionals and administrative staff. The majority of included studies used quantitative study designs (24 studies), 12 used mixed methods and five used qualitative designs. All quantitative studies were quasi-experimental and most employed a single group design. Only two studies had a comparison group. In general, qualitative study designs were not specified. None of the included studies reported providing any form of certification. Positive outcomes were reported in the included studies at a number of levels, specifically, reactions ( 23 studies), attitudes ( 28 studies), skills/knowledge ( 24 studies), individual behaviour ( 27 studies) and organisational practice ( 8 studies). While most of included studies were based on self-reported data, it was reported that 17 studies which reported on 
behavioural change gathered observational data. In conclusion, the authors stated that their review found "a number of innovative Faculty Development programs in this area. Participants value these activities and report changes in attitudes, skills, and behaviour. Moreover, despite methodological limitations, certain program characteristics seem to be associated with positive outcomes." (p501).

\section{Steinert et al. (2016)}

These authors updated their 2006 review which aimed to understand the effects of Faculty Development interventions on the knowledge, attitudes and skills of teachers in health professions education (which extended the focus of their original review from medical education). Four databases were searched from 2002 to 2012. In addition, hand searches of journals, conference proceedings, reference lists of all review articles and experts' recommendations were undertaken. After screening of potential materials, 111 studies were located from 17 countries including USA, UK, Canada, Sweden, Australia, Demark, Germany and Italy. Study participants included clinical teachers from medicine, nursing, dentistry, social work and speech therapy. The aims of the included Faculty Development interventions focused on the improvement of teaching performance (in the classroom and the clinical setting) as well as teaching/learning approaches, the acquisition of specific teaching skills, learner assessment skills and curriculum development skills. The duration of Faculty Development interventions ranged from 30 minutes to four years and were delivered in workshops, short courses, seminar series and longitudinal courses. None of the included studies reported providing any form of certification. Of the included studies, the majority were quasi-experimental and used single-group designs (83 studies) of which 39 included pre-post-test designs and 44 used post-tests only designs. In addition, 42 of these studies included a delayed post-test. Sixteen of the studies employed control groups. Twenty-five of the studies employed a mixed-methods approach. Seven studies used a qualitative methodology while four studies used randomized controlled designs, and one study used a prospective observational design. Positive outcomes which were reported in this update included studies at a number of levels, specifically, reactions/satisfaction (56 studies), attitudes (51 studies), skills/knowledge (60 studies), individual behaviour (72 studies), organisational practice ( 26 studies) and among learners of the teachers/faculty developers ( 5 studies). Again, although most of included studies were based on selfreported data, it was reported that 39 studies which reported on behavioural change gathered observational data. The authors conclude that since their initial review published in 2006 the "breadth of Faculty Development programs described in the literature continues to grow at a rapid rate. Moving forward, implications for practice include building on our successes to date, broadening our focus beyond individual teaching effectiveness, developing programs that extend over time, moving from workshops to the workplace, fostering communities of practice, and securing institutional support. [There is also a need for] embedding research studies in a theoretical or conceptual framework, conducting more qualitative and mixed methods studies, using multiple methods and data sources to assess behavioural and organizational outcomes, assessing change and transfer to practice over time, analysing key features of Faculty Development, and exploring the role of Faculty Development within the larger organizational context" (p14). 